\title{
SUEÑOS DE IDENTIDAD: LENGUAJE, MITO E «HISTORIA» EN LA DOCTRINA DE LA RAZÓN DE ESTADO
}

\author{
POR \\ José ANTONio MARTínez TORRES \\ Hispania Sacra \\ «El ordenamiento de la sociedad \\ era obra de Dios, y su concepción del \\ futuro se hallaba ligada a la venera- \\ ción del pasadon.
}

J. H. ElLiOTT'

\section{Resumen}

La asimilación de la historia de España por Castilla es un hecho que arranca del siglo XIII, se adormece en el XIV y se relanza en el XV. No obstante, es durante el reinado de Felipe IV (1621-1665) cuando se origina todo un proyecto historiográfico castellanista que, grosso modo, insiste en la unidad del reino de España, así como en vincular la dinastía de los Austrias a los reyes godos.

\section{AbStract}

The assimilation of the history of Spain by dawns in the thirteenth century, it appeases in the fourteenth century and it is relaunched in the fifteenth century. Notwithstanding, it is during Felipe IV's reign (1621-1665) lohen a full-length historiographic project originates in support of Castile which, broadly, emphasizes the unity of the kingdow of Spain as well as the historical links between the Austrias dynasty and de Goth kings.

1 El Conde-Duque de Olivares. El Polltico en una Epoca de Decadencia, (Barcelona, Crítica, $6^{*}$ edición), página, 658. 


\section{DE UN JURISTA, DE UN LIBRO, Y DE LA DISPUTA POR LA PREEMINENCIA DE LA CRISTIANDAD.}

Las Excelencias de la Monarchia y Reyno de España $\left(1625^{2}\right)$, es el libro que sirve de excusa para presentar apretadamente a Gregorio López Madera. Un tradicional y reputado jurista que escribió en abundancia y que ejerció importantes cargos públicos dentro del aparato de la monarquía durante los reinados de Felipe II, Felipe III y Felipe IV $^{2}$. Asimismo, también es un pretexto para mostrar una serie de elementos que se repiten de forma sistemática en esta obra y en la de otros autores — muy cercanos al poder central— de la «razón de Estado» castellana.

Acaso las Excelencias no es el más importante de los textos de López Madera, pero si el que más polémica ha generado, y el que, actualmente, dispone de una reciente edición $n^{3}$.

El libro en particular ha sido objeto de repetidas confusiones en cuanto a la fecha de elaboración de la primera y segunda edición.

La propuesta aquí sostenida indica la redaccion anterior a 1593 (fecha en que se autoriza la impresión de la primera edición), exactamente entre 1588 y 1592. Varias razones avalan esta hipótesis: sus contenidos responden al contexto de renovación de la idea imperial castellana de las décadas de los ochenta y noventa del siglo XVI, con motivo de la anexión de Portugal a la Monarquía hispánica 4 . Otra razón para respaldar los años señalados es la vinulencia de los argumentos esgrimidos contra Francia en la secular disputa que enfren-

2 PELORSON, Jean Marc, Les letrados, juristes castillans sous Philippe III: recherches sur leur place dans la societé, la culture et l'état, (Poitiers, 1980), pp. 87, 132, 221, 249, 295, 324, 356-357, 373, 462, 478 y 499. Úlimamente, de DIOS, Salustiano, «El Absolutismo Regio en Castilla durante el siglo XVI», lus Fugit, vol. 5-6, (1996-1997), pp. 53-236. Existe una breve biografía, así cono una glosa crítica de la producción bibliográfica de este Jetrado en, MARTíneZ TORRES, José Antonio y GARCtA BALLESTEROS, Enrique, «Gregorio López Madera (1562-1649): un jurista al servicio de la coronas, Torre de Los Lujanes, 37, (1998), pp. 163-178.

3 Vid., el meritorio trabajo de BERMEjo CABRERo, José Luís, Excelencias de la Monarchia y Reyno de España, (Madrid, CEPC, 1999), con introducción. Todas las citas que en este articulo se hacen a la obra de López Madera son de esta edición, que se fundamenta en las de 1597 y 1625; a este libro me remito para mayores precisiones.

${ }_{4}$ BIGALLI, Davide, Immagini del Principe. Ricerche su politica e umanesimo nel Portogallo $e$ nella Spagna del Cinquecento, (Milán, Franco Angeli, 1985), passim, durante la primera mitad del siglo XVI el humanismo portugués venía formulando todo un proyecto de imperio concordante con el castellano; y Bouza ÁlVAREZ, Fernando, «De archivos y antiguas escrituras en la pretensión al trono portugués de Felipe II. La unión de coronas ibéricas de un fin de siglo a otron, en Imagen y propaganda. Captulos de historia cultural del reinado de Felipe II, (Madrid, Akal, 1998), pp. 121-133. Recientemente, VALLADARES, Rafael, Portugal y la monarquia hispánica, 1580-1668, (Madrid, Arco libros, 2000).

Actas del I Congreso de Historia de la Iglesia y el Mundo Hispánico Hispania Sacra 52 (2000) 
taba a la dinastia Habsburgo con la Valois, por justificar si la mayor preeminencia correspondía al título de «católico» o al de «cristianísimo»5. La inestabilidad sucesoria que atraviesa el reino francés, debido a la falta de heredero al fallecer Francisco de Anjou en 1584, hacen que algunos postulados de las Excelencias tengan sentido. Esto es patente en la defensa que hace López Madera de la sucesión femenina como la más conforme al derecho de gentes, justo cuando se barajaba la posibilidad de que la hija de Felipe II, Isabel Clara Eugenia, heredase el trono francés ${ }^{6}$.

No es disparatado suponer que la obra se silenciara —-durante la alianza entre los católicos franceses y españoles en la Liga de 1585-, como censura a las descalificaciones de este letrado a propósito de ciertas cuestiones jurídicas sobre la soberanía de los reyes españoles manifestadas por Jean Bodin, Charles Dumoulin y Barthélemy Chasseneuz ${ }^{7}$. Las réplicas, sin embargo, no tardaron en surgir. Así, en 1610, Jérôme Bignon publica un Traité de l'excellence des Rois et du Royaume de France, donde se contraatacaba severamente las posturas defendidas por López Madera en las Excelencias, pero sobre todo las de Jaime Valdés en De Dignitate Regum regnorumque Hispaniae (1602); obra que venía a presentar a España como la «caput Europae», y a Felipe III como el mejor de los candidatos posibles al Imperio ante la complicada cuestión hereditaria que se vaticinaba en los dominios de Rodolfo $\Pi^{8}$.

5 CRAVAliz, Agustín de, Sumario de diversas historias para probar que el Rey de España ha de preceder al Rey de Francia, BNM, mss 887, folios 301-328; del mismo: Discurso sobre las precedencias de España y Francia, BNM, mss 1022, folios 2.44.

6 IVDJ, envio 7, I, folios 230-231: «Estratto del secondo thomo del libbro del stato della chiesa composto da Guglielmo de Preau dottor in theologia ... impresso per Guglielmo Chaudiere il anno 1583 con permission del Re, Permostrare che Philipo ReCatholico di Spagna e ... del sangre nobbile et anticho per linea mascolina di padre infiglio di Clovis Redi francia primochristiano per la genealogia che segue...». Sobre la Ley Sálica, BARUDIO, Günter, La época del absolutismo y la ilustración, 16481779, (Madrid, Siglo XXI, $6^{2}$ edición 1992; $1^{2}$ en alemán, 1981), pp. 75-82, especialmente, página, 78.

7 KELLEY, Donald R, Foundations of Modem Historical Scholarship, (Columbia U. P. 1970), capitulos VI y VII; SALMON, J. H. M, «Clovis and Constantine. The Uses of History in Sixteenth Century Gallicanism», in Journal of Ecclesial History, vol. 41, $\mathrm{n}^{\circ}$ 4, (october 1990), pp. 584-605, y la bibliografía allí citada. La repulsa de los publicistas españoles a Jean Bodin en, ALBURQUERQUE, Martim de, Jean Bodin na Pentnsula lbérica. Ensaio de historia das ideias polfticas $e$ de direito público, (Paris, Fundaçao Calouste Gulbekian, Centro Cultural Português, 1978), pp. 77-118. Asimismo, BODIN, Jean, Los seis libros de la República, (Madrid, Tecnos, $2^{\circ}$ edición 1992; selección, traducción y estudio preliminar de Pedro Bravo Gala), Libro I, capítulo IX: «Del Principe Tributario o Feudatario y si es Soberano, y de la Prerrogativa de Honor entre los Principes Soberanos», pp. 66-72, especialmente, páginas, 70 y 71 .

8 Sobre este punto: ZeLLER, Gaston, «Les rois de France candidats à l'empire: essai sur 1 1'idéologie impériale en France», Revue Historique, 173, (1934), pp. 273-331 y 497-543; BENEYTO, Juan, Espafia en la gestación historica de Europa, (Madrid, IEP, 1975), pp. 403-405 y 412 413; EVANS, R. J. W., Rudolf II and his World, (Oxford, Clarendon Press, 1973), capínlos I y II; FERNÁNDEZ Albaladejo, Pablo, Fragmentos de Monarquia. Trabajos de Historia Poltitica, (Madrid, 
Cuando en 1597 se publiquen las Excelencias, a un año del Edicto de Nantes y de la Paz de Vervins, la situación había cambiado considerablemente. La muerte de Felipe II destapa esa crisis que comienza a gestarse con la derrota de la Armada en 1588. Es el momento propicio para idealizar algunos reinados, y para establecer un lenguaje político que reivindique para la Monarquía hispánica la perfección que tuvo en la época de Isabel y Fernando.

Los últimos años de Felipe III, todavía muy desatendidos historiográficamente $^{10}$, se prestan de puente y maduración para una tratadística castellanista que reclama imparcialidad en la administración de justicia, defensa de la fe, decoro en las costumbres, unidad política, religiosa, e incluso de santidad ${ }^{11}$; asimismo, prepara el terreno a la política de reputación del conde-duque de Olivares, derivada del fin de la pax hispanica.

En 1625, después del Gran Memorial, y a un año escaso de la Unión de Armas, sale una segunda edición ampliada de las Excelencias. Aunque la situación política era diferente a la de finales del siglo XVI, grosso modo, el mensaje de López Madera podía tener algún sentido. No existe ninguna prueba documental que garantice que la obra formaba parte de la operación propagandística de Olivares, pero no es absurdo suponer que algo había detrás. Y es que, el ideario político de Gregorio López Madera y de Baltasar Álamos de Barrientos, por citar a dos autores paradigmáticos de la hegemonización de España por Castilla, era un apoyo para los propósitos del valido: encumbrar a Felipe IV a la mayor grandeza de todas, esto es ser «Rey de España» ${ }^{12}$.

Alianza Universidad, 1992), pp. 67-72, especialmente, páginas, 69 y 70; y LUTZ, Heinrich, Reforma y Contrarreforma, (Madrid, Alianza Universidad, 1992; $1^{*}$ en aleman, 1982), pp. 166 169, y en general todo el apartado 21 .

9 EllotT, J. H., El Conde-Duque... Op cit., pp. 110-111, y todo el capitulo 3: «La herencia reformista».

10 Exceptuando los estudios de John Elliott, Irving Thompson, Patrick. L. Williams y Pérez Bustamante, disponemos de FEROS CARRASCO, Antonio, "Política interior. El régimen de los validos», pp. 10-67, esp, páginas, 60 y ss; y SIMON TARRÉs, Antoni, «La política exterior», pp. 335-465, especialmente, pp. 348-356; ambos en Antonio Donnínguez Ortiz (dir.), Historia de España, (Barcelona, Planeta, vol. 6: «La crisis del siglo XVII», 1988), a los que sigo en este aspecto.

11 GonZÁlez PALENCLA, Ángel, La Junta de Reformación, (Valladolid, 1932), passim; EllioTt, John H., El Conde-Duque... Op cit., pp. 327-328, donde se informa de la disputa entre los partidarios de Santiago y los de Santa Teresa; FRtAS, L, «Felipe III y la Inmaculada Concepción. Instancias a la Santa Sede por la Definición del Misterio", Razon y Fe, tomos X, XI, XII y XIII (1904), pp. 21-33, 145-156, 293-308, 180-198, 322-336 y 62-75, respectivamente; y LOPEZ MADERA, Gregorio, Tratado de la Concepcion Inmaculada de la Santissima Virgen Maria nuesrra (sic) señora sobre el Psalmo 44: «Enuctauit cor meum verbum bonum» (Madrid, 1638), BNM 3-11. 193.

$12 \mathrm{El}$ memorial del conde-duque de Olivares no puede entenderse ignorando otra serie de proyectos simultáneos a éste y que, en cierto modo, completaban el diseño del valido al apostar por el monoconfesionalismo territorial, y por la reunificación política de las dos ramas de la casa de los Habsburgo. Vid., FERNÁNDEZ ALbaLADEJo, Pablo, «El Problema de la 'composite monarchy' en España», en

Actas del I Congreso de Historia de la Iglesia y el Mundo Hispánico

Hispania Sacra $52(2000)$ 


\section{ARGUMENTOS CASTELLANISTAS PARA LA UNIDAD Y LA IDENTIDAD DE LAS ESPAÑAS.}

En el contexto histórico en el que se desenvolvían las monarquías de los siglos XVI y XVII: de irresolución de la crisis estructural del orden político medieval, la apelación al profetismo y al universalismo no debe contemplarse como un obstáculo para el desarrollo del naciente estado moderno. Al contrario, estos supuestos estrechamente vinculados con la tradición política de la Edad Media, fueron un alimento indispensable para aquéllas monarquías que, como la española, hicieron del universalismo y del profetismo el «fundamento constitutivo de su propia identidad» ${ }^{13}$. Sólo así se comprende que Isabel I sea cantada por Spenser como Astrea, la Reina de las Hadas, la Reina Virgen, la Reina iluminada por el sol de la religión, y por la caridad cristiana; que la monarquía sueca - sistematizando la mitología griega, hebrea, y las profecías de Paracelso y Tycho Brahe- se anuncie como «el seno de la segunda Epifanía y de la paz universal»; o que, finalmente, Enrique IV, arquetipo de monarca centralista en los manuales al uso, sea presentado por la panfletística francesa como el «Hércules Gálico» y «ce grand Roy de la Fleur de Lys ... appeté par les propheties à la Seignurie du Monde» ${ }^{14}$.

Gregorio Lopez Madera, en las Excelencias, irá más lejos que los autores indicados, ya que sus pretensiones son «demostrar» que el «Rey de España» es el verdadero poseedor del título de monarcha. Para tal propósito dispone de una serie de elementos que legitiman su argumento: la antigüedad, la continuidad y la prudencia.

Así, comienza explicando el sentido de monarcha y la acepción por él utilizada. Si monarcha se tomara, dice, como significado de «señor universal del mundo», la titulación sólo podía recaer en Cristo; si la acepción empleada fuera la de monarcha como «qualquiera que solo gouierna, o rige algun Rey-

BURDELL, Isabel and CASEY, James (eds.), Identities: nations, provinces and regions, 1550-1900, (Norwich, School of History, University of East Anglia), pp 185.201, especialmente, página, 194, apoyándose en resultados de STRAUB y ERNST,

13 Fernández AlbaladeJo, Pablo, Fragmentos de Monarquia... Op cit., pp. 170 y 171.

14 Para Inglaterra, YATES, Frances A, Astraea. The imperial theme in the sixteenth century, (Londres, Routledge \& Kegan Paul, 1975), pp. 1-28 y 208-214; y La Filosofia Oculta en la Época Isabelina, (México, FCE, 1982), pp. 163-188. El ejemplo de Suecia lo cita SIMON TARRÉs, Antoni, «La política exterior»... Op cit., página, 352. Para Francia, VIVANTT, C, Lotta politica e pace religiosa in Francia tra Cinque e Seicento, (Torino, Einaudi, reed. 1974), página, 104, citado por FERNÁNDEZ ALBALADEjo, Pablo, Fragmentos... Op cit., página, 169. Asimismo, buenas consideraciones de conjunto en, ARMITAGE, David (ed.), Theories of empire 1450-1800, (Aldershot, Ashgate Varionum, 1998), passim; y BOSBACH, Franz, Monarchia Universalis. Storia di un concetto cardine della politica europea (secoli XVI-XVIII), (Milano, Vita e Pensiero, 1998; 1" en alemán 1988), capítulos III y IV. 
no», todo rey podía considerarse monarcha. Esta es la razón para que sólo se denomine monarchia al reino más poderoso «y que mas Reynos y Prouincias (tiene) sujetas». Acreditación que López Madera reservaba exclusivamente para España, pues sus territorios, a diferencia de los de las otras monarchias, siempre habían sido ganados por «justissimas causas y aprovados titulos», nunca recurriendo a «la violencia y fuerza de las armas».

El hecho de señalar que Hispaniae era una monarchia compuesta por una pluralidad de títulos y territorios, no era un impedimento para afirmar que la monarchia de España era una unidad reconocible bajo el título de «Rey de España», ni que el derecho del título «siempre estuvo... en los Reyes de León y Castilla». En efecto, Castilla era la «cabeça de España» y a la que el resto de reinos debían «superioridad y vassallage» por su condición de restauradora providencial del «solar» hispánico en la guerra contra el Islam. Es más, el proceso de reconquista legitimaba el título de monarcha para el rey de España, y a su monarchia le garantizaba tener la cualidad de ser la única con carácter de auténtico «imperio respecto de sí misma».

Tales afirmaciones, sin duda, se nutren del modelo historiográfico castellanista que proporcionan la Historia Gothorum de Isidoro de Sevilla, la Historia Gothica de Rodrigo Jiménez de Rada, y, sobre todo, la Anacephaleosis de Alfonso García de Santa María, autor que recuperó en el siglo XV el viejo mito castellano neogodo para ponerlo al servicio de las aspiraciones castellanas de ocupación de un puesto preeminente en la Europa de las nationes ${ }^{15}$.

López Madera también resaltará la antigüedad del reino de España, que a instancias de Florián de Ocampo y Ambrosio de Morales, era «la mayor que (había) en el mundo», si bien acababa vinculándose a Castilla.

La continuidad quedaba reflejada en la sucesión de padres a hijos, y en el caso del monarcha castellano era ininterrumpida desde Don Pelayo: «ut in tota Europa non ualeret simile reperire», citando las palabras de García de Santa María en sus Allegationes ${ }^{16}$. Al igual que el obispo de Burgos, en López Ma-

15 TATE, Robert B., Ensayos sobre historiografía pensinsular del siglo XV, (Madrid, Gredos, 1970), pp. 55-73; CAMLlo Ottavio di, El Humanismo Castellano del Siglo XV, (Valencia, Fernando Torres Editor, 1976), capitulos V y VI; HiLLGARTH, J. N., Los reinos hispánicos, 1250-1516, (Barcelona, Grijalbo, 3 vols. 1983), vol. 2: «La hegemonia castellana, 1410-1474», pp. 222-224, especialmente, páginas, 223 y 224; CATALÁN, Diego, «Introducción» a MENÉNDEZ PIDAL, Ramón: Los españoles en la historia, (Madrid, Espasa-Calpe, 3* edición 1991), pp. 9-73, especialmente, páginas, 40-53; FERNÁNDEZ VALVERDE, Juan, «Introducción» a JiMENEZ de RADA, Rodrigo: Historia de los hechos de España, (Madrid, Alianza Editorial, 1987), pp. 13-52; y MARAVALL, José Antonio, «La morada vital hispánica y los visigodos», en Estudios de Historia del Pensamiento Español, (Madrid, Ediciones Cultura Hispánica, Serie Primera, 1967), pp. 393-409.

16 Folio 36 v; en Ja misma línea: SALAZAR de MENDOZA, Pedro, Monarchia de España, (Madrid, 1770-71), fol. 277; CASTLLo, Julián del, Historia de los reyes godos, (1624; reedición ampliada

Actas del I Congreso de Historia de la Iglesia y el Mundo Hispánico Hispania Sacra 52 (2000) 
dera la equivalencia Rex Gothorum, Rex Hispaniae y Rex Castellae es completa, y concede a los reyes castellanos el soporte jurídico necesario para ser los «único(s) heredero(s) legítimo(s) del reino de España en toda su extensión» ${ }^{17}$.

Es, sin embargo, una virtud, la prudencia, la que cataliza una parte importante en las Excelencias de la Monarchia y Reyno de España. López Madera combina dos concepciones de la idea de tirano: de un lado, la vieja idea clásica, presente en el pensamiento grecorromano y rescatada por el arzobispo de Reims, Hincmar, que consideraba la tiranía como un gobierno injusto. Por otro, sigue vigente la desviación del concepto originado por San Pedro, que recogerá San Isidoro y que, finalmente, establece Orosio: tirano es el mal gobernante $o$ el que se rebela contra el legítimo titular del poder ${ }^{18}$. Estas posturas llevan a Madera a tomar de San Agustín una noción de la tiranía como gobierno injusto pero permitido por Dios, que trae a colación con motivo de la explicación de que el derecho divino no pertenece a los reyes, sino al derecho de gentes:

«... que el poder y autoridad de los Reyes infieles no menos procede de Dios, con ser verdad, que no les pertenece a ellos el derecho Diuino. Los quales son de los que permite la diuina prouidencia... Dios... quiere los Reyes legitimos, y los gouienos justos, y permite los tiranicos y injustos... y quando vsamos desta palabra, permission, no es porque no sea Dios autor de toda potestad... sino porque no lo es de la mala administracion, ....

En definitiva, la eficaz administración del reino no es potestad de Dios, sino que es un mal cuyo único responsable es el titular de la corona. Asimismo, la prudencia es la virtud que hace que un rey sobresalga en las tareas de gobierno y administración de justicia. Significa, además, una correcta aplicación de la tradición a la práctica política. Por tanto, el apelativo de «prudente» a un rey, lo convierte, desde esta perspectiva, en referencia histórica obligada y en paradigma de gobierno ejemplar ${ }^{19}$.

de la de 1582); SAavedra Fajardo, Diego, Corona Gótica, Castellana y Austraca, (1645); Obras (Madrid, Atlas, 1947); MÁRQUEZ, Joseph Michel, Trono Real Gotico Castellano y Austriaco en España, (1655), RAH 9-466.

17 CATALÁN, Diego, «Introducción»... Op cit., página, 45.

18 MARIANA, Juan đe, La Dignidad Real y la Educación del Rey, (Madrid, CEC, 1981; $1^{\text {a }}$ edición, 1599), capítulo V: «Diferencia entre el Rey y el Tirano»; y el estudio introductorio de SÁNCHEZ AGESTA, Luis, «El Padre Juan de Mariana, un humanista precursor del constitucionalismo», pp. IXLXV, especialmente, páginas, XIII-XXVI y XLI-LIII.

19 BOUZA Ál VAREZ, Fernando, «La fortuna historiográfica de Felipe II entre los siglos XVI y XX. Pérdida y recuperación de la personalidad histórica del Rey Católicon, en El Escorial. Biografia de una epoca. (La Historia), (Madrid, Fundación para el apoyo de la cultura / Dirección General de Bellas Artes y Archivos, 1986), pp. 310-361; ElLLOTT, J. H., El Conde-Duque... Op cit., pp. 102, 110. $121,183-188,198$ y 375. 


\section{BREVE INCURSION EN OTRAS LÍNEAS DISCURSIVAS.}

«No deu ésser rei qui no té la llei e no serve aquella ... príncep que no serva fe a sos vassalls, per infesaltat de vassalls ha morir». «Nos que valemos tanto como vos os hacemos nuestro Rey y Señor, con tal que nos guardéis nuestros fueros y libertades, de lo contrario, now ${ }^{20}$. Ambas frases, justificativa de la rebelión la una, legalista la otra, son una muestra del espíritu que subyacía en el constitucionalismo catalano-aragonés. Su discurso recorre una singular cultura política que hunde sus raíces en los textos de Francesc de Eiximenis, Pere Belluga, Jaume Callís, Tomás Mieres, Jaume Marquilles, Jerónimo de Blancas, Pedro Calixto Ramírez y Frances de Gilabert y d'Alentorn, por citar algunos autores. Y es que, el constitucionalismo catalano-aragonés, al contrario que el «decisionismo jurídico castellano», fue una «alternativa» a la teoría absolutista de Jean Bodin contenida en Les Six Livres de la République (1576), la cual tuvo mejor acogida en Castilla ${ }^{21}$. Por supuesto, el pensamiento político castellano de los siglos XV, XVI y XVII no estaba conformado por un corpus ideológico estático: fue más dinámico de lo que se venía afirmando. Así, los cincuenta últimos años del siglo XVI son testigos de una importante renovación en la tradición escolástica castellana, a causa de incorporar en sus obras el pensamiento de Comelio Tácito, a través de Justo Lipsio, y la doctrina del «antimaquiavelismo» por mediación de Pedro de Ribadeneyra. El echar mano de tales recursos, señala Antoni Simon Tarrés, no restó originalidad a la tratadística castellana, pero desde el primer momento dejaba patente su imposibilidad de conciliar dos exigencias que ya eran contradictorias en la Europa de la Contrarreforma: el reforzamiento del Estado, y la subordinación de éste a una auctoritas de índole metapositivo, como era la de la ley divina ${ }^{22}$.

20 El primer entrecomillado dice lo siguiente: «No debe ser rey quien no tiene la ley y no sirve a aquélla ... príncipe que no guarda la fe a sus vasallos, por infidelidad de vasallos ha de morirn, citado por HILlgarTH, J. N., Los reinos hispánicos... Op. cit., vol. 2, página, 227; la segunda frase en, ELLIOTT, John H., La España Imperial, 1469-1716, (Barcelona, Ediciones Vicens Vives, $4^{\text {a }}$ reimpresión, 1993; 1" en inglés, 1963), página, 25.

21 LaLinde ABadía, Jesús, «El Pactismo en los Reinos de Aragón y de Valencia», en Legaz LACAMBRA, Luís et al., El pactismo en la Historia de España, (Madrid, Instituto de España, 1980), pp. 115-139; y del mismo, «La creación del derecho entre los españoles», Anuario de Historia del Derecho Español, 36, (1966), pp. 301-377, de donde tomo las expresiones. Para el pactismo en Aragon: GIESEY, Ralph, If not, not. The Oath of the Aragonese and the legendary Laws of Sobrarbe, (Princeton U. P. 1968); GIL PUJOL, Xavier, «Aragonese constitutionalism and Habsburg rule: the varying mearning of liberty", in KAGAN, Richard and PARKER, Geoffrey (eds.), Spain, Europe and the Allantic World. Essays in honor of John H. Elliott, (Cambridge U. P.), pp. 160-187; y GASCón PéREZ, Jesús, «Los fundamentos del constitucionalismo aragonés. Una aproximación», Manuscrits, 17, (1999), pp. 253-275.

${ }_{22}$ SIMON TARRÉs, Antoni et al., Historia de España. La España del Siglo XVII. Los Austrias Menores. Polftica y Cultura en la Edad Moderna, (Espasa, vol. 6, 1999), pp. 20-24, especialmente, 
El siglo XIX todavía es un hito importante para el constitucionalismo catalano-aragonés, así lo acreditan los trabajos de Manuel Lasala, Víctor Balaguer, Javier de Quinto y Manuel Dánvila, aunque el peso de estos autores en Europa no es comparable al que tuvieron en los siglos modernos la publicística nombrada al inicio de este apartado. Antaño, el influjo del constitucionalismo catalano-aragonés fue notorio en algunas cortes europeas, dejándose sentir en Venecía, con Juan de Soranzo, en Francia, de la mano de los monarcómacos Teodoro de Beza y François Hotman, e incluso llegó a Castilla, donde Mariana y Marquéz son sus mejores representantes ${ }^{23}$. No obstante, si exceptuamos a los últimos autores citados, puede afirmarse que el pactismo castellano fue exiguo en comparación con el catalano-aragonés, quedando prácticamente relegado al arbitrismo fiscal ${ }^{24}$.

Aproximadamente desde el siglo XIII existe una corriente historiográfica castellanista que asimilaba la «Historia de España» a Castilla. El siglo XIV supuso una inflexión para esa historiografía, si bien pronto fue relanzada con la publicación en 1455 de la Anacephaleosis. Este texto, obra de Alfonso García de Santa María, ha sido considerado por Robert B. Tate como «uno de los primeros testimonios explícitos de la consciencia de Castilla de su propio pasado». En efecto, el converso obispo de Burgos recupero el mito neogótico, le otorgó una dimensión europea, y, finalmente, fijó un estereotipo del que se van a servir —en los siglos XVI y XVII- Florián de Ocampo, Pedro de Medina, Esteban de Garibay, Gregorio López Madera y Diego Saavedra Fajardo ${ }^{25}$. Tales autores divulgan una «Historia de España» en la que la exposición de los acontecimientos es realizada en clave castellanista. No obstante, la respuesta a esta corriente historiografica surge pronto y en los diferentes rincones de la Monarquía hispánica: desde Nápoles a Portugal, pasando por Aragón y Cataluña, todos los territorios van a considerarse la «millor Espanya» y su más excelente cabeza. Castilla no era la única protagonista en esa «Historia de España»; también lo eran Cataluña y Aragón, y sus publicistas e historiadores estaban dispuestos a refutar —en el mismo terreno- los polémicos argumen-

página, 21 y 22; FERNÁNDEZ ALBALADEJo, Pablo, Fragmentos... Op. cit.. pp. 72-85, especialmente, páginas, 73 y 74; y ALBURQuerQUe, Martin de, Jean Bodin na Península Iberica. Ensaio de história ideias polfticas e de direito público, (París, Fundą̧ao Calouste Gulbenkian, Centro Cultural Português, 1978), pp. 121-145.

${ }_{23}$ LaLINDE ABAdfA, Jesús, «El Pactismo en los Reinos... Op. cit., página, 137; GIESEY, Ralph E., If not, not. The Oath of the Aragonese and the Legendary Laws of Sobrarbe, (Princeton U. P. 1968), página, 244; y GASCÓN PÉREZ, Jesús, «Los fundamentos del constitucionalismo... Op. cit., página, 255

24 SIMON TARRes, Antoni et al., Historia de Espanta... Op. cit., página, 22.

25 Ś́lo indico algunos autores representativos, pues la relación de escritores en esta línea discursiva es extensa; es más, llega a los siglos XVIII, XIX y XX. Sobre este aspecto estoy preparando un trabajo: «La Asimilación de la Historia de España por Castilla». 
tos esgrimidos por sus homónimos castellanos ${ }^{26}$. Señalaré algunos ejemplos de todo esto.

1557 es la fecha de publicación de texto de Cristofor Despuig Los Colloquis de la insigne ciutat de Tortosa, en cuya línea pueden hallarse múltiples y sugerentes testimonios como este: «La major part dels castellans gosen dir públicament que aquesta nostra provincia no és Espanya y per ço que nosaltres no som verdaders espanyols ...» pero «aquesta nostra provincia no sols és Espanya mas és la millor Espanya ....»27

El Analyticus Tractatus de Lege Regia (1616) es el título abreviado de un original libro de Pedro Calixto Ramírez, en el que aparte de realizarse una meritoria interpretación de los fueros de Aragón en clave de historia romana, diferente de la que venía practicándose, también se mantiene la tesis de integrar en una maxima regio --Hispania- a las seis magnae regiones que conformaban la Monarquía hispánica: Castilla, Navarra, Cataluña, Valencia, Portugal y Aragón. La defensa de esta postura, sin duda, supuso un duro golpe a esa publicística empeñada en señalar que la identidad de Hispania residía en la dinastía. El verdadero componente identitario, señalaba Calixto Ramírez, lo proporcionan los diferentes territorios ${ }^{28}$; además, el hecho de que Felipe III fuera el rey de todos ellos debía considerarse como una cuestión fortuita:

«Maxima autem regio plures ac diversas, magnas regiones comprehendit intra suos fines, \& territorium, ut Hispania, intra quam sunt magnae regiones, supra numeratae (Castella, Navarra, Cathalonia, Valentia, Lusitania, Aragonia) quae pyrineis montibus circunscribitur ... ac sub uno catholico, ac domino nostro Rege Philippo gubernatur, \& regitur: que tamen, sub maioribus regionibus comprehendetur, ut sunt Europa, Asia, vel Africa. Ex quibus omnibus, licet parva, \& magna regio semper ab uno capite regantur, indeque proprie regiones apellatae, tamen maxime \& maiores non semper, nec necessario, sed ex accidenti, uni capiti subsunt, ac in unum regem pervenerunt .... 29

26 FERNÁNDEZ Albaladejo, Pablo, «El problema de la 'composite monarchy' en España»... Op. cit., página, 193.

${ }^{27}$ DURAN, Eulalia (ed.), Los Colloquis de la insigne ciutat de Tortosa, (Barcelona, Universidad de Barcelona / Editorial Curial, 1981), página, 102; también ha llamado la atención sobre este texto, BELENGUER CEBriÀ, Ernest, «La Monarqúa Hispánica vista desde la Corona de Aragón», Estudis, 20, (1994), pp. 57-73, autor que recoge otros testimonios para insistir.

28 Es decir, espacios en los que convergen una determinada comunidad y un derecho. Cfr., BRUNNER, Otto, Estructura interna de Occidente, (Madrid, Alianza Universidad, 1991; versión espanola de Antonio Sáez Arance y Julio Antonio Pardos; $1^{*}$ en alemán, 1978), pp. 102-117, especialmente, páginas, 103-105; y del mismo autor: Terra e Potere. Strutture pre-statuali e pre-modeme nella storia costituzionale dell Austria Medievale, (Milano, Giuffre, 1983; 1" en alemán, 1939).

29 FERNÁNDEZ Albaladejo, Pablo, «El problema de la 'composite monarchy'... Op. cit., página, 198; este autor también ha adelantado investigaciones sobre Calixto Ramírez; «Lex regia aragonensium: monarquía compuesta e identidad de reinos en el reinado de Felipe III», Congreso Intermacionál España y Suecia en la Época del Barroco (1600-1660), Madrid, 13-17 de octubre de 1997,

Actas del I Congreso de Historia de la Iglesia y el Mundo Hispánico Hispania Sacra 52 (2000) 
Francesc Martí Viladamor, doctor en leyes, y uno de los principales ideólogos de la revuelta catalana de 1640, es el autor de Noticia Universal de Cataluña, un texto que criticaba duramente la política del conde-duque de Olivares y el argumento de las Excelencias de la Monarchia y Reyno de España. Así, el último capítulo de su trabajo se dedica a desarmar la tesis de Gregorio Lopez Madera, jurista del que viene a decir que «más con leyes de adulación que de derecho» había legitimado «... los intentos del Privado en reduzir a un solo Reyno todos los de España». La ubicación de la crítica a López Madera al final de su libro no era casual, subraya Fernández Albaladejo, ya que los veintitrés capítulos anteriores estaban destinados a invalidar la tesis de la unicidad del reino de España. A grandes rasgos, Noticia Universal de Cataluña mantiene las siguientes posturas: la pluralidad de reinos; la autoridad de Cataluña para «mudar de govierno»; y, finalmente, el origen de la libertad catalana en los tiempos de Tubal: «el primer fundador de España». Además, Martí Viladamor consideraba Cataluña como un laboratorio de experimentación, «un primer paso» en las pretensiones de Olivares, es decir: «reduzir a su obedienzia y a las leyes de su gusto todo el reynon. La nobleza no podía obviar su papel equilibrista en ese delicado momento, tenía que asumir responsabilidades, pues «perdida Cataluña lo sería toda España ${ }^{30}$.

Estos pocos testimonios, que de ninguna manera pretenden ser exhaustivos, reflejan la tensión que existía entre unos historiadores que hegemonizaban España por Castilla, y otros que, sin salirse del marco jurídico-plural en el que se desenvolvía la Monarquía hispánica, también pugnaban por un lugar preeminente en la «Historia de España».

Frente a la manipulación de lo que se viene denominando el «hecho histórico diferencial», en cualquiera de sus acepciones, una reciente historiografía de historia política está perfilando un proceso de configuración de las distintas comunidades políticas del Antiguo Régimen europeo, bastante más común de lo admitido tradicionalmente. Por de pronto, parece ser que el desarrollo hist6rico-político originario de Gran Bretaña, así como el de una determinada «British History», tiene alguna que otra semejanza con el de España y una carente "Historia de España»31. Todavía queda mucha labor de zapa de textos, pero

(policopiado); y GIL PUJOL, Xavier, «Las Cortes de Aragón en la Edad Moderna: Comparación y Reevaluación», Revista de las Cortes Generales, 22, (1991), pp. 80 y 94 . Agradezco a Yolanda Martínez Torres sus precisiones en la traducción del texto latino.

30 Fernández Albal.ADEJo, Pablo, «El Reinado de Felipe IV: 'Reformación' de la Monarquía y 'Guerras de Espafia' w, separata del estudio preliminar a las Actas de las Juntas del Reino de Galicia. Volumen II: 1630-1636, (Xunta de Galicia, 1997), pp. 57-73, especialmente, páginas, 69 y 70.

31 FeRNÁNDeZ Albaldejo, Pablo, «El problema de la 'composite monarchy', Op. cit., siguiendo a PoCocK, John, «British History. A Plea for a New Subject», Journal of Modem History, 47, 
no faltan sugerentes orientaciones para analizar éstos. Tal es la de Enric Ucelay $\mathrm{Da}-\mathrm{Cal}$, autor que propone una reorientación en el estudio de las guerras civiles españolas (incluida la revuelta catalana de 1640); éstas no deben ser analizadas sólo como el fruto de las desgracias históricas: también son acontecimientos históricos clave en «la construcción de las formas políticas hispáni-

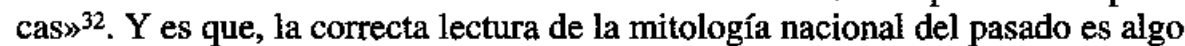
que compete a todos, pero lo que desde luego no corresponde es distorsionar la Historia para legitimar nuestro presente.

\section{BIBLIOGRAFIA.}

Alburquerque, Martin de, Jean Bodin na Peninsula Ibérica. Ensaio de historia ideias politicas e de direito páblico, (París, Fundaçao Calouste Gulbenkian, Centro Cultural Português, 1978).

ARMTTAGE, David (ed.), Theories of empire 1450-1800, (Aldershot, AshgateVarionum, 1998).

Belenguer CEBriA, Emest, «La Monarquía Hispánica vista desde la Corona de Aragon», Estudis, 20, (1994), pp. 57-82.

BosBaCH, Franz, Monarchia Universalis. Storia di un concetto cardine della politica europea (secoli XVI-XVIII), (Milano, Vita e Pensiero, 1998; $1^{2}$ en alemán, 1988).

BURDEL, Isabel and CASEY, James (eds.), Identities: nations, provinces and regions, 1550-1900, (Norwich, School of History, University of East Anglia, 1999).

CASTRo, Américo, España en su historia: cristianos, moros y judios. (Barcelona, Crítica, 1983, $2^{\mathrm{a}}$ edición).

CIRUJANo Marín, P, Elorriaga, T, y PéreZ Garzon, Juan-Sisinio, Historiografia y nacionalismo español, 1834-1868, (Madrid, CSIC, 1985).

ElliotT, J. H, El Conde-Duque de Olivares. El Político en una Época de Decadencia, (Barcelona, Crítica, 6edición, 1991; $1^{\star}$ en inglés, 1986).

(1975), pp. 601-621; del mismo: «Deconstructing Europe», History of European Ideas, vol. 18-3, (1994), pp. 329-345.

32 UCELAY-DA CAL, Enric, «Nationalism in Spain. Some Interpretative Proposals», in BURDIEL, Isabel and CASEY, James (eds.), Identities: Nations, Provinces and Regions, 1550-1900, (Norwich, School of History, University of East Anglia, 1999), pp. 7-52, el entrecomillado en la página, 9, y más áun: «... sólo será posible superar el lastre del 'excepcionalismo' hispánico, en cualquiera de sus acepciones, mediante un esfuerzo por integrar toda la problemática ibérica (cuestiones lusas incluídas) en un contexto analítico genuinamente europeo.»; asimismo, el trabajo de Fernández Albaladejo citado en la nota anterior, los que están en curso por PérEZ GARZÓN, Juan-Sisinio y RIVIĖRE GómEZ, Aurora y el de BURDIEL, Isabel, «Liberalismo y nacionatismo en la historiografía reciente. El fracaso como identidad compartidaw, Op. cit. pp. 55-64; todos estos trabajos ofrecen bibliografía para insistir en estos aspectos.

Actas del I Congreso de Historia de la Iglesia y el Mundo Hispanico Hispania Sacra $52(2000)$ 
Fernández AlbaladeJo, Pablo, Fragmentos de Monarquía. Trabajos de Historia Politica, (Madrid, Alianza Editorial, 1992).

FERNÁNDEZ SANTAMARÍA, J. A. Razón de Estado y política en el pensamiento español del barroco (1595-1640), (Madrid, CEC, 1986).

GIESEY, $\mathrm{R}$, If not, not. The Oath of the Aragonese and the legendary Laws of Sobrarbe, Princeton U. P. 1968)

GIL PUJOL, Xavier, «Visió Europea de la monarquia espanyola com a monarquía composta, ss XVI i XVI», Recerques, 32, (1995), pp. 19-43.

- «Aragonese constitunionalism and Habsburg rule: the varying mearnig of liberty» in Richard L. Kagan and Geoffrey Parker (eds.), Spain, Europe and the Atlantic World. Essays in honour of John H. Elliott, (Cambridge U. P. 1995), pp. 160-187.

LOMONACO, F, Lex Regia. Diritto, filologia e fides historica nella cultura politicofilosofica dell'Olanda di Fine del Seicento, (Nápoles, Guida, 1990).

IÑURRTEGUI, José María, La Gracia y la República. El lenguaje político de la teología católica y el Príncipe Cristiano de Pedro de Ribadeneyra, (Madrid, UNED, 1998).

KEARNEY, Hugh, Las Islas Británicas. Historia de cuatro naciones, (Madrid, Cambridge U. P. 1999, $1^{\circledR}$ en inglés, 1989; traducción de Julio Antonio Pardos Martínez; epílogo de Pablo Fernández Albaladejo).

PAGDEN, Anthony et al., The Languajes of Political Theory in Early-Modern Europe, (Cambridge U. P. 1987).

Pocock, J. G. A., The Machiavellian Moment. Florentine Political Thought and The Atlantic Republican Tradition, (Princeton U. P. 1975).

PRIETO BERNaBE, José Manuel, «Prácticas de lectura erudita en los siglos XVI y XVII», separata de Escribir y leer en el siglo de Cervantes, Barcelona, Gedisa, 1999, pp. 30.

RUBIES, Joan Pau, «The concept of empire in the catalan tradition from Ramon Muntaner to Enric Prat de la Riba", in Journal of Hispanic Research, IV, (1995-1996), pp. 229-262.

SIMON TARRÉS, Antoni et al., «Pensament polític de la Corona d'Aragó i l’època dels Austria», Manuscrits, 17, (1999), pp. 203-340.

SKINNER, Quentin, Los fundamentos del pensamiento polftico modemo, (México, FCE, 1986, 2 vols; $1^{2}$ en inglés, 1978)

TATE, Robert B., Ensayos sobre historiografia peninsular del siglo XV, (Madrid, Gredos, 1970).

YATES, Frances A, Astraea. The imperial theme in the sixteenth century, (Londres, Routledge \& Kegan Paul, 1975).

- La Filosofía Oculta en la Época Isabelina, (México, FCE, 1982; $1^{\mathrm{a}}$ en inglés, 1979). 